\title{
Simulation and Analysis on the Effect of Static Synchronous Compensation Device on HVDC Commutation Failure
}

\author{
Qiaoqiao Li \\ North China Electric Power University, Beijing, 102206 \\ qiaoqiaocindy@126.com
}

Keywords: STATCOM; HVDC; Commutation failure; Operation performance

\begin{abstract}
As the second generation of FACTS products, static synchronous compensator (STATCOM) can dynamically compensate for the reactive power of the system, thereby improving the operating characteristics of the system. The STATCOM is connected to the HVDC inverter AC bus, and the HVDC transmission system model with STATCOM is established. The effect of STATCOM on the commutation failure and DC power recovery time is studied by PSCAD / EMTDC simulation in different types and levels of fault. The simulation results show that the access of STATCOM can improve the immunity of HVDC system to commutation failure, accelerate the recovery of DC transmission power and improve the running characteristics of the system.
\end{abstract}

\section{Introduction}

HVDC transmission has the advantages of large transmission capacity, fast controllable power regulation, low line cost, non-synchronous networking capability and reliable operation. It has obvious advantages in long-distance and large-capacity transmission and large area networking. So it has been widely used in our country, which is such a vast territory and uneven distribution of natural resources. But the operation of HVDC depends on the end of the grid, extremely sensitive to the failure of the AC system. A rectifier or inverter station disturbance may cause the inverter commutation failure, resulting in DC power transmission interruption.

STATCOM, one of the key members of the FACTS family, enables continuous reactive adjustment in the entire range of inductive to capacitive, especially under-voltage conditions, which has a great significance in improving the independence of HVDC system against commutation failure. As document referred, recently, China Southern Power Grid has STATCOM applied to HVDC transmission projects.

Currently, many domestic and foreign scholars have also carried out an in-depth study on STATCOM and HVDC transmission system commutation failure. Document analyzed the operational reliability of large-capacity STATCOM. Document proposed the use of STATCOM to test LCC-HVDC to supply power to the passive network. Document studied the influence of STATCOM on the operating characteristics of double-infeed HVDC system. Document studied the characteristics of the $\mathrm{AC}$ system itself and influence of different types of reactive power compensation devices on HVDC commutation failure recovery. However, there is little research on STATCOM's quantitative analysis of HVDC system under different kinds of fault.

In this paper, the commutation failure immunity index (CFII) is used to measure the capacity of the system to resist commutation failure. The most serious fault condition of single-phase ground fault and three-phase ground fault is simulated in PSCAD / EMTDC. The difficult or easy degree of commutation failure and the time of failure recovery with and without STATCOM are compared. The significance of static synchronous compensation device to suppress commutation failure and improve system stability is illustrated.

\section{Commutation Failure of HVDC}

As the most typical system fault of HVDC transmission system, commutation failure will cause the $\mathrm{AC}$ voltage to drop, the DC current to increase for a short time and so on. The continuous 
commutation failure causes even the interruption of DC power transmission ${ }^{[7]}$. In general, the voltage drop caused by short circuit fault of the AC system is the main reason for commutation failure $^{[8]}$.

Principle of Commutation Failure. In the converter, during the action period of reverse voltage, if the exit valve fails to recover its blocking capability or the reverse voltage is not ended during the commutation process, then when the voltage of the valve becomes positive, the commutating valve will be commutated to the valve intended to exit. As described in document this station is called commutation failure. Most of the commutation failure in HVDC system occur in the inverter. Therefore, this paper connects STATCOM to the AC side of the inverter to study the influence it acts to commutation failure of the inverter.

Criterion of Commutation failure. It is generally believed that the inverter fails when the turn-off angle $\gamma$ of the valve is less than its inherent limit turn-off angle $\gamma_{\min } . \gamma_{\min }$ can be described as the time required for the carrier compound switch to establish the P-N junction barrier and restore positive blocking capability in the thyristor. The corresponding electrical angle is usually around $10^{\circ}{ }^{[9]}$. After removing the margin, deionization recovery time is $400 \mu$ s (about $7^{\circ}$ ) or so.

At present, $50 \mathrm{HZ}$ component value of the DC current, comparison of the DC current value and the three-phase AC current, the off-angle judgment method and the minimum voltage drop method are commonly used in the project as the commutation failure criterions. In this paper, DC current and valve side AC current comparison method is used as the criterion ${ }^{[10]}$.

\section{Modeling of HVDC System with STATCOM}

\section{Modeling of the STATCOM Subsystem.}

Working principle. The working principle of STATCOM is to connect VSC (Voltage Source Converters) to the grid through a series reactance. According to the reactive power and active power command of the input system, the amplitude and phase of the output voltage of the AC side of the bridge circuit are adjusted appropriately. Direct control of the current of its AC side can also make the circuit to absorb or send the required reactive current to achieve the purpose of dynamic reactive power compensation. The main circuit is shown as Fig.1.

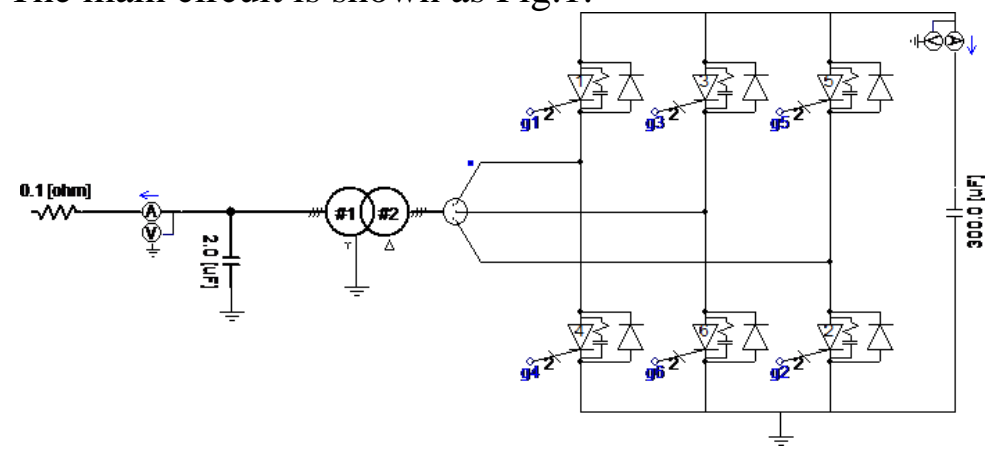

Figure 1 The main circuit of HVDC

Control Strategy. The model uses the AC voltage control strategy. Through the closed-loop feedback control, it can dynamically change the value of $\delta$ angle, thus changing the reactive current injected into the system, and ultimately achieve the purpose of adjusting the system voltage. In the control circuit, the error signal obtained by subtracting the filtered voltage from the reference voltage is passed through the lead-lag PI correction link, and finally the angle of the angle is obtained.

Model Parameters. The model parameters are as follows: the system rated voltage is $230 \mathrm{kV}$. The reference capacity is 100MVA. Transformer winding voltage is $230 \mathrm{kV} / 25.0 \mathrm{kV}$. Leakage resistance is $0.1 \mathrm{pu}$. The transformer is connected to the AC bus through a $0.1 \Omega$ resistor and a $2 \mu \mathrm{F}$ grounding capacitor. 
Effects and Significance. As illustrated in Document, STATCOM plays an important role in suppressing bus voltage oscillation and improving system transient voltage stability. As a result, it can provide reactive compensation for the system and stabilize the AC bus voltage ${ }^{[11]}$, which can suppress commutation failure to a certain extent. For failure which is not very serious, it can also play a role in mitigation and support.

Modeling of HVDC System

Model Illustration. The HVDC system in this paper is a single-stage system based on the CIGRE standard test model of the international large grid standard test system. This model is used to illustrate the basic control strategy and fault response characteristics of conventional HVDC systems. The control method for the rectifier measurement are DC current control and minimum trigger angle control, and for the inverter side are DC current control and turn-off angle control. In addition, both the rectifier and inverter sides are equipped with a low voltage current limit (VDCOL), and the inverter side is equipped with a current error controller (CEC $)^{[12]}$.

Model Parameters. The HVDC system parameters are also selected based on the CIGRE model parameters, which are shown in the following table 1.

Table 1 Parameters of HVDC

\begin{tabular}{ccccccc}
\hline \hline \multicolumn{2}{c}{ LCC-HVDC system rated parameters: $500 \mathrm{kV}, 1000 \mathrm{MW}, 50 \mathrm{~Hz}, \mathrm{DC}$ side: $\mathrm{R}=5 \Omega, \mathrm{L}=1.2 \mathrm{H}$} \\
\hline $\begin{array}{c}\text { AC system } \\
\text { in Rectifier side }\end{array}$ & $\begin{array}{c}\text { Compensation } \\
\text { capacity of } \\
\text { reactive power } \\
\text { in Rectifier side }\end{array}$ & $\begin{array}{c}\text { Converter } \\
\text { transformer } \\
\text { in Rectifier } \\
\text { side }\end{array}$ & $\begin{array}{c}\text { AC system } \\
\text { in Inverter side }\end{array}$ & $\begin{array}{c}\text { Compensation } \\
\text { capacity of } \\
\text { reactive power } \\
\text { in Inverter side }\end{array}$ & $\begin{array}{c}\text { Converter } \\
\text { transformer } \\
\text { in Inverter side }\end{array}$ & SCR \\
& & & & & & \\
\hline $382.8 \mathrm{kv}$ & $626 \mathrm{MVA}$ & $603.7 \mathrm{MVA}$ & $215.0 \mathrm{kV}$ & $626 \mathrm{MVA}$ & $591.8 \mathrm{MVA}$ & 2.5 \\
$47.7 \angle 84.25^{\circ} \Omega$ & & $345 / 213.5 \mathrm{kV}$ & $21.2 \angle 75^{\circ} \Omega$ & & $230 / 209.2 \mathrm{kV}$ & \\
& & $0.18 \mathrm{pu}$ & & & $0.18 \mathrm{pu}$ & \\
\hline \hline
\end{tabular}

The STATCOM subsystem is tested in PSCAD and connected to the inverter AC bus to form the HVDC system with STATCOM.

\section{Simulation and Result Analysis}

\section{Description of the Simulation.}

The influence of STATCOM on HVDC commutation failure is reflected by the commutation failure critical impedance, commutation failure immune index and fault recovery time.

The Maximum Fault Ground Impedance. The maximum fault grounding impedance causing the commutation failure is collectively referred to as the commutation failure critical impedance $Z_{\text {fault }}$, indicating the fault ground impedance when $\gamma=\gamma_{\min }$ due to the inverter side AC fault in this paper ${ }^{[13]}$. The process to find the critical impedance is an optimization process. According to document, that is to select a criterion to solve the commutation failure critical impedance using PSCAD continuous simulation in different fault types, different fault times and different ground impedance range.

Commutation Failure Immunity Index. The commutation failure immunity index (CFII) is used to measure the difficult and easy degree of commutation failure, which is defined as follows.

$$
C F I I=\frac{V_{a c}^{2}}{Z_{f a u i t} P_{d c}}
$$

In Eq.1, $P_{d c}$ is the DC rated power. $V_{a c}$ is the rated line voltage. It can be seen from Eq. 1 that this index is related to the rated line voltage, the DC transmission rated power and the commutation failure critical impedance. According to document, the larger the index value, the greater the ability of the inverter to resist the commutation failure is, the less the risk of the commutation failure is. 
In addition, according to document [13], in HVDC system, the inductive ground fault in AC bus of the inverter side is the most serious fault type. Therefore, in this paper, the inductance ground fault is selected to determine the CFII value.

$$
C F I=\frac{V_{a c}^{2}}{\omega L_{\min } P_{d c}}
$$

In Eq.2, $L_{\min }$ is the minimum ground inductance value in which the DC system does not undergo commutation failure at any time when the fault occurs under the chosen fault type.

The Fault Recovery Time. In this paper, the fault recovery time is defined as the time that the HVDC system active power is restored to $90 \%$ of the one before fault occurs, to describe the transient characteristics of HVDC ${ }^{[14]}$.

\section{Simulation and Analysis of Results.}

Based on the DC transport system model with STATCOM in PSCAD / EMTDC, we can find the most serious moment of failure by using the Multirun module in PSCAD / EMTDC software , setting 100 fault points at intervals of $0.02 \mathrm{~s}$ in one cycle, in the single-phase ground fault and three-phase ground fault respectively. And then we record the grounding impedance in the presence and absence of STATCOM case when commutation failure just not occurs.

Fig. 2 and Fig.3 compare the operating characteristics in the event of a system failure in two different cases with and without STATCOM. All values in the figure are per-unit values. Table 2 and Table 3 compare the failure recovery time in the same failure level and CFII of different fault types.

The Single-Phase Ground Fault Simulation. At the time of $0.809 \mathrm{~s}$, in the cases with and without STATCOM, the single-phase ground fault occurs with a grounded inductance of $1 \mathrm{H}$, and the duration of the fault is $0.1 \mathrm{~s}$. The simulation model parameters are selected as described above.

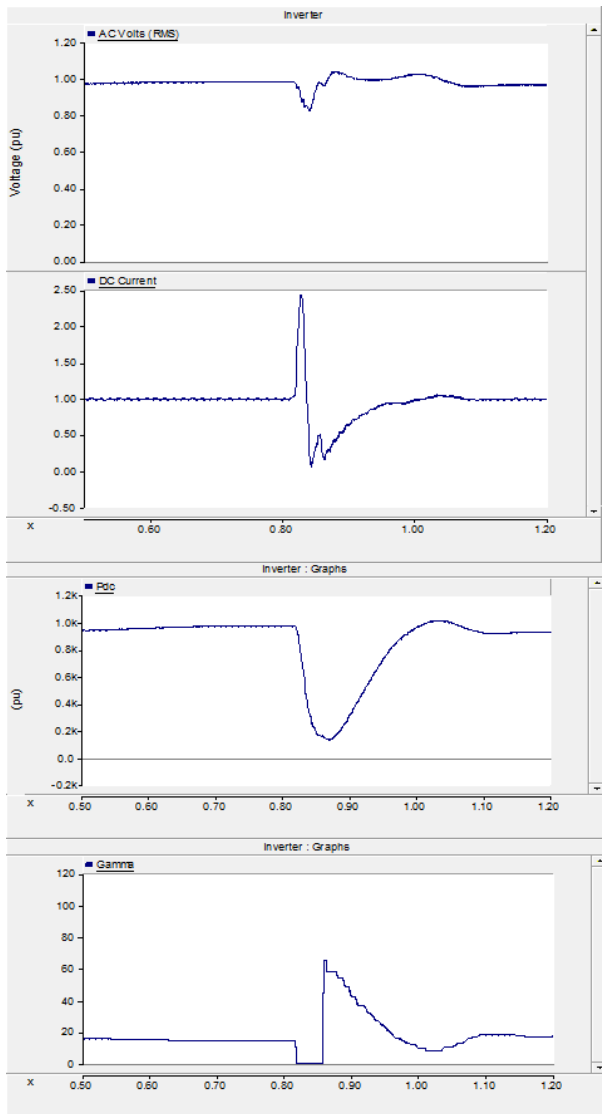

(a)without STATCOM

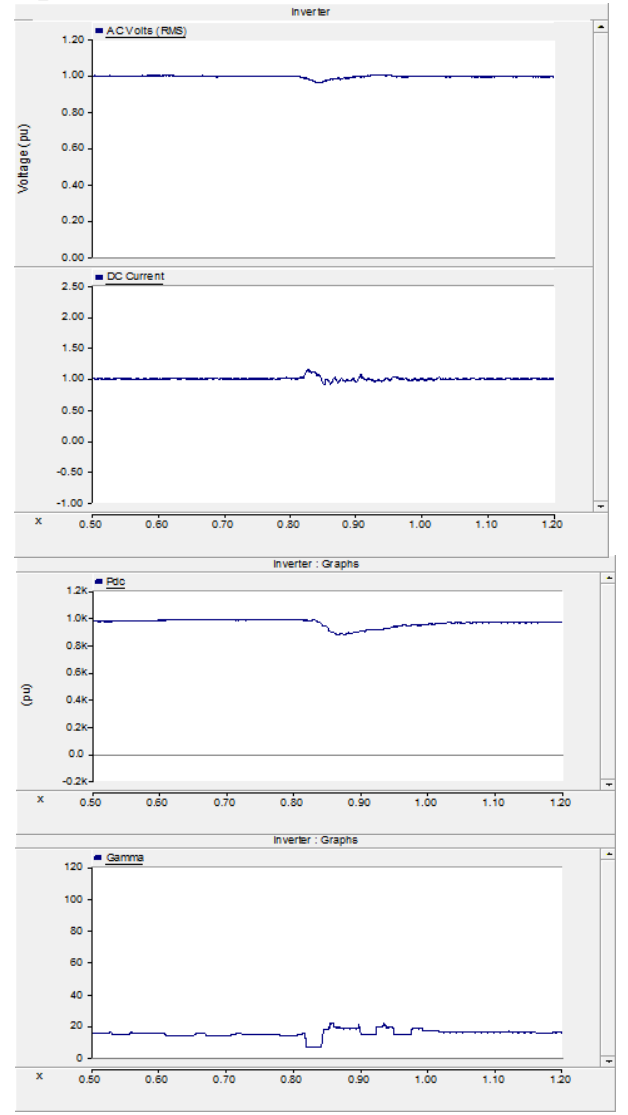

(b)with STATCOM

Figure 2 Operation performance of the single-phase ground fault 
Three-Phase Ground Fault Simulation. At the time of 0.809 s, in the cases with and without STATCOM, the system has a three-phase ground fault with a grounded inductance of $1 \mathrm{H}$, and the duration of the fault is $0.1 \mathrm{~s}$. The simulation model parameters are selected as described above.

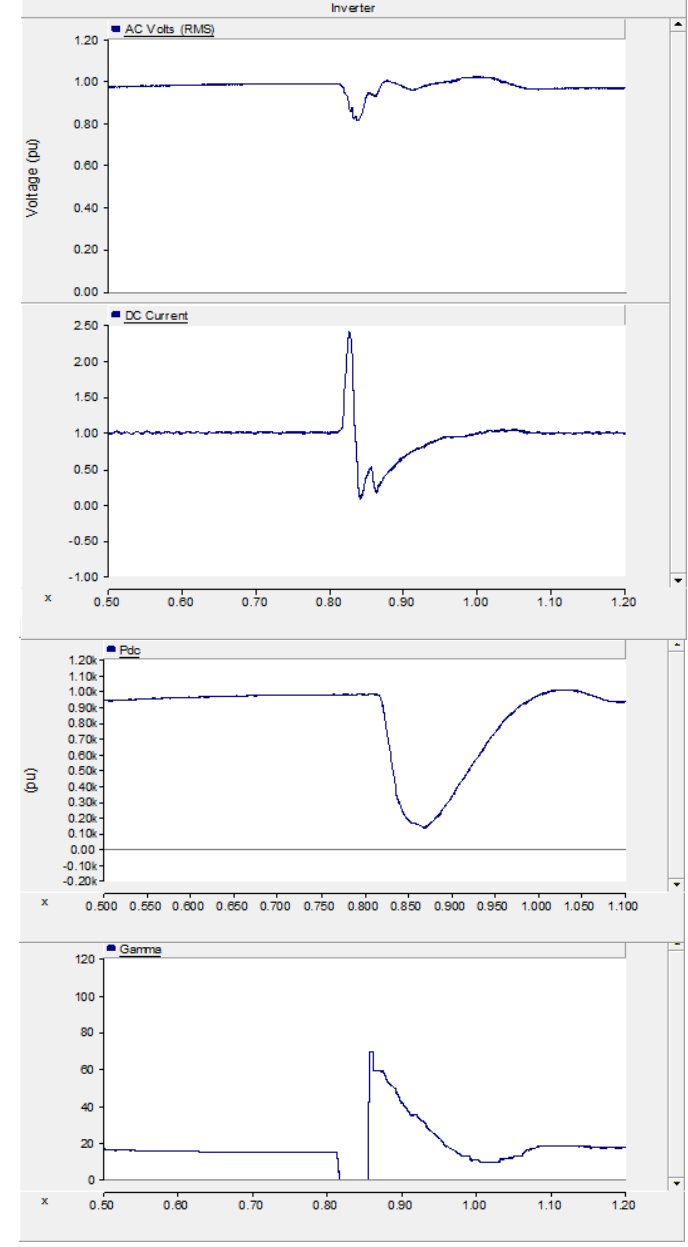

(a) without STATCOM

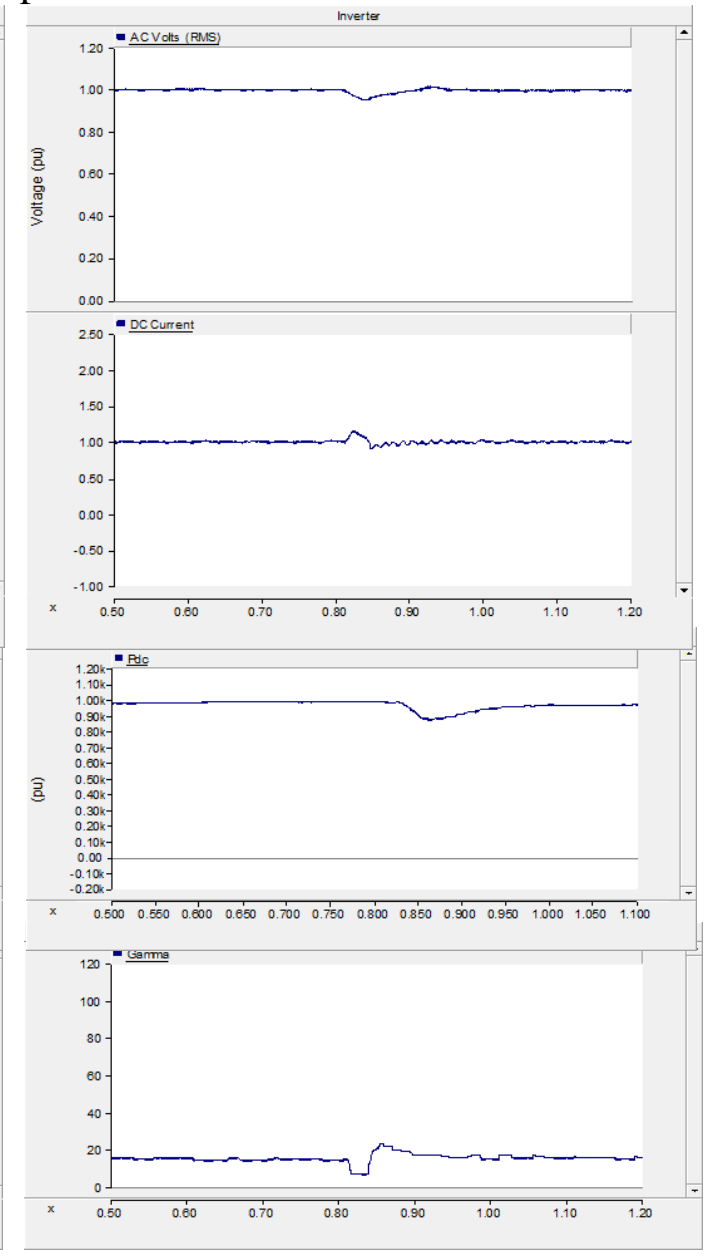

(b)with STATCOM

Figure 3 Operation performance of three-phase ground short-circuit fault

Analysis of Results. Fig.2 (a) and Fig.3 (a) show the operating characteristics when the HVDC is not connected to STATCOM. We can see that after the fault, the DC voltage and the transmission of the active power of the line rapidly reduced. The DC current rose and the turn-off angle is reduced to around $0^{\circ}$. The system commutation fails. Connect 100MVA STATCOM to the system, and the simulation results are shown in Fig.2 (b) and Fig.3 (b). Compared to (a), the STATCOM provides reactive compensation for the system, stabilizing the AC bus voltage, limiting the voltage and power to fluctuate in a small range, and the turn-off angle rises to $7^{\circ}$. In this case, the system does not fail. The data of simulation results are shown in the following Table 2 and Table 3.

Table 2 The failure recovery time in the same failure level

\begin{tabular}{ccccc}
\hline Fault type & $\begin{array}{c}\text { The moment } \\
\text { of } \\
\text { failure } \\
{[\mathrm{s}]}\end{array}$ & $\begin{array}{c}\text { Inductance } \\
\text { to the } \\
\text { ground } \\
{[\mathrm{H}]}\end{array}$ & $\begin{array}{c}\text { Fault recovery } \\
\text { time }\end{array}$ & $\begin{array}{c}\text { Fault recovery } \\
\text { without STATCOM }\end{array}$ \\
$\begin{array}{ccccc}\text { time } \\
\text { with STATCOM } \\
{[\mathrm{s}]}\end{array}$ \\
\hline Single-phase ground fault & 0.809 & 1.000000 & 0.080 & 0 \\
Three-phase ground fault & 0.809 & 1.000000 & 0.075 & 0.001 \\
\hline
\end{tabular}


Table 3 Critical impedance and CFII of different fault types.

\begin{tabular}{cccccc}
\hline \multirow{2}{*}{ Fault type } & \multicolumn{2}{c}{ without STATCOM } & \multicolumn{2}{c}{ with STATCOM } & degree \\
& $\begin{array}{c}\text { Critical } \\
\text { impedance }\end{array}$ & $\begin{array}{c}\text { CFII } \\
{[\%]}\end{array}$ & $\begin{array}{c}\text { Critical } \\
\text { impedance }\end{array}$ & $\begin{array}{c}\text { CFII } \\
{[\%]}\end{array}$ & $\begin{array}{c}\text { of } \\
\text { improvement } \\
\end{array}$ \\
& {$[\mathrm{H}]$} & & {$[\mathrm{H}]$} & & \\
\hline Single-phase ground fault & 1.007445 & 16.71 & 0.804438 & 20.93 & 25.27 \\
Three-phase ground fault & 1.285022 & 13.10 & 0.945596 & 17.81 & 35.95 \\
\hline
\end{tabular}

The result proves that in the weak AC system with short circuit ratio (SCR) of $2.5,100 \mathrm{MVA}$ STATCOM can effectively reduce the probability of commutation failure, increase commutation failure immunity and accelerate the recovery of DC transmission power, thus increasing stability of the system.

\section{Conclusion}

(a) This paper introduces the concept and calculation method of critical impedance and immune level of commutation failure. Furthermore, this paper illustrates the control strategy of the STATCOM, and then builds the HVDC simulation model with STATCOM in PSCAD / EMTDC.

(b) In this paper, the effect of STATCOM on the failure level and failure recovery time of the inverter system are compared. It's found that STATCOM can improve the operating characteristics of the whole system, accelerate the recovery of DC transmission power and effectively improve the immunity of HVDC system to commutation failure.

(c) Under different fault types, STATCOM can improve the immune level of commutation failure in different degrees. In this model, for the single-phase ground fault, the level can be increased by $25.27 \%$. For the three-phase ground fault, the immune failure level can be increased by $35.95 \%$.

\section{References}

[1] Zhejiang University HVDC Research Group. DC transmission [M].Beijing, China: Electric Industry Power Press, 1982: 16-17.

[2] ZHAO Chengyong, LI Dan, LIU Yuchao, et al. Control method for HVDC system with STATCOM [J]. High Voltage Engineering, 2014, 40(8): 2440-2448.

[3] GAO Mingzhen, HE Gang, HU Guangzhen, et al. Reliability evaluation of 100 MVA STATCOM [J]. High Voltage Engineering, 2013, 39(7): 1784-1791.

[4] Nayak B, Gole A M, Chapman D G, et al. Dynamic performance of static and synchronous compensators at an HVDC inverter bus in a very weak AC system [J]. IEEE Transactions on Power Systems, 1994, 9(3): 1350-1358.

[5] Oliveira M D, Poloujadoff M, Du a L, et al. Supply of an entirely passive AC system through an HVDC link [J]. International Journal of Electrical Power \& Energy System, 1994, 16(2): 111-116.

[6] GUO Chunyi, ZHANG Yanpo, ZHAO Chengyong, et al. Impact of STATCOM on the operating characteristics of double-infeed HVDC system[J]. Proceedings of the CSEE, 2013, 33(25): 99-106.

[7] WANG Gang, LI Zhikeng HUANG Min, et al. Influence of initial fault voltage angle on commutation failure identification in a HVDC system[J]. Automation of Electric Power Systems, 2010, 34(4): 49-54, 102.

[8] WU Chong, LI Xingyuan, HE Chaorong. Application of multi-infeed interaction factor in South Grid commutation failure research[J]. Relay, 2007, 35(9): 26-31.

[9] OU Kaijian, REN Zhen, JING Yong, et al. Research on commutation failure in HVDC transmission system part 1: commutation failure factors analysis[J]. Electric Power Automation Equipment, 2003, 23(5): 5-8, 25. 
[10]ZHANG Yanpo. Basic study on using STATCOM to improve the operating characteristics of DC transmission system [D]. Beijing, China: North China Electric Power University, 2013: $19-49$.

[11]ZHOU Chang-chun, XU Zheng. Simulation and analysis of recovery characteristics of HVDC connected to AC system with weak strength [J].Power System Technology, 2003, (11):18-21.

[12]XU Zheng. Analysis of dynamic behavior of AC/DC power system [M]. Beijing, China: Machinery Industry Press, 2004: 39-44.

[13]E. Rahimi, A. M. Gole, J. B. Davies, et al. Commutation Failure in Single-and Multi-Infeed HVDC Systems[C]. The 8th IEE International Conference on AC and DC Power Transmission, 2006: 182-186

[14]GUO Chunyi. Fundamental performances research on the novel hybriddual-infeed HVDC system [D]. Beijing, China: North China Electric Power University, 2012: 18. 